This is the final peer-reviewed accepted manuscript of:

Journal of Biomechanics: Volume 48, Issue 5, 18 March 2015, Pages 787-796

In vitro evidence of the structural optimization of the human skeletal bones

LucaCristofolini

PMID: 25596628

The final published version is available online at:

https://doi.org/10.1016/i.jibiomech.2014.12.010

Rights / License:

The terms and conditions for the reuse of this version of the manuscript are specified in the publishing policy. For all terms of use and more information see the publisher's website.

This item was downloaded from IRIS Università di Bologna (https://cris.unibo.it/)

When citing, please refer to the published version. 


\title{
In vitro evidence of the structural optimization of the human skeletal bones
}

\author{
Luca Cristofolini, Ph.D. \\ ${ }^{1}$ Department of Industrial Engineering, School of Engineering and Architecture, \\ University of Bologna, Viale Risorgimento 2, 40136 Bologna, Italy
}

\section{Submitted to: J. Biomechanics}

Special Issue dedicated to the memory of Rik Huiskes

Version.0: $\quad 9^{\text {th }}$ December 2013

Version.1: $\quad 30^{\text {th }}$ July 2014

Corresponding author:

Luca Cristofolini

Department of Industrial Engineering

University of Bologna

Viale Risorgimento, 2

40136 Bologna, Italy

e-mail: luca.cristofolini@unibo.it 


\section{$1 \quad$ ABSTRACT}

2 Optimization can be seen in a number of human skeletal bones. While there is strong

3 evidence concerning the mechanism at the tissue-level for bone adaptation to the

4 applied loads, the structural optimization at the organ-level is somewhat less clear.

5 This paper reviews the evidence, mainly based on in vitro testing, but also from

6 anatomical and biomechanical considerations, concerning the shape-function

7 relationship in some exemplar cases. The proximal femur is robustly optimized to

8 resist a force applied in a range of directions during daily life, but also to absorb a

9 large amount of energy if an impact is delivered on the greater trochanter during a

10 sideways fall. The diaphysis of the tibia is shaped so as to act as a uniform-stress

11 structure (i.e. structurally efficient) when loaded by a bending moment in the sagittal

12 plane, such as during locomotion. The body of the thoraco-lumbar vertebrae is

13 optimized to resist to a load applied strictly in an axial direction. The result of this

14 review suggests that the structure of bones derives from a combination of local

15 stimulus-driven tissue-level adaptation within the subject, and organ-level generational

16 evolution.

\section{Keywords:}

18 Robust optimization; shape and function; evolution; bone strength; robustness;

19 functional adaptation 


\section{INTRODUCTION}

21 The structure of skeletal bones has called the attention of scientist for centuries. In the

22 nineteenth century, anatomy studies combined with modern mechanics provided the

23 first evidence that the arrangement of the trabeculae of cancellous bone is strongly

24 related to the biomechanical function. In 1856 Swiss engineer Karl Culmann

25 remarked the similarity of the trabecular arrangement in the proximal femur, and that

26 of the "Culmann crane" he had recently designed (Crystal, 1998). Few decades later

27 Julius Wolff gave the first formal description of the optimization principle underlying

28 the structure of bones (Wolff, 1892). While Wolff focussed on the mechanical

29 description of such an optimized design, it was Wilhelm Roux who first introduced the

30 concept of a quantitative self-regulatory mechanism as an explanation for such an

31 optimal structure (Roux, 1881). Shortly later, John Koch provided a thorough

32 theoretical analysis of the stress distribution in the proximal human femur, including a

33 first estimate of the safety factor for the femoral neck (5.7, both for the maximum

34 tensile and compressive stress) (Koch, 1917). With the advent of contemporary

35 biology, a hundred years later it became possible to describe a cellular mechanism

36 capable of managing bone adaptation (Carter, 1984; Roesler, 1987). Although the

37 principles of bone adaptation (misleadingly known as "Wolff's law") have often been

38 put under discussion (Bertram and Swartz, 1991; Huiskes, 1995), its general principles

39 remain valid, and are the backbone of modern bone biomechanics (Cowin, 2001;

40 Currey, 1982; Fung, 1980; Roesler, 1987).

41 It was Dennis Carter who provided a first description of the bone apposition/resorption

42 balance in response to cyclic loading, in the form of an algorithm (Carter, 1984),

43 which was soon converted into numerical models based on finite element (FE) analysis

44 (Huiskes et al., 1987). The principles of bone adaptation were incorporated in FE 
45 models initially to predict adaptation of bone to the presence of an implant (e.g.

46 (Huiskes et al., 1989; Huiskes et al., 1992)). With the advancement of the

47 understanding on the control mechanism of bone cells, FE models became capable of

48 predicting trabecular morphology (i.e. sizes and branching of struts) in relation to the

49 local loads (Huiskes et al., 2000; Mullender et al., 1994; Ruimerman et al., 2005b).

50 Predictions of bone adaptation based on such local optimization criteria have been

51 validated qualitatively (Huiskes, 1993). More recently, quantitative validation has

52 become possible thanks to the advancement of high-resolution in vivo imaging

53 (Lambers et al., 2011).

54 While local adaptation has extensively been explored at the tissue-level, its up-scaling

55 to the organ-level has only partially been accomplished (e.g. (Kuiper et al., 1991)).

56 Optimization of the shape of bones to achieve the maximum resistance with the

57 minimum amount of material has been for long hypothesized (Roux, 1881). It has

58 recently been stated that measuring bone strains can improve the understanding of

59 bone shape-function relationships (Demes, 2007). Several studies suggest that bone

60 geometry and density are adjusted by bone remodelling so as to attain a constant level

61 of stress/strain (e.g.: (Lanyon, 1980)). A recent study when contralateral bones of the

62 human lower limbs were compared (Cristofolini et al., 2014) showed that the

63 differences in stiffness observed at the whole-bone level are mainly explained by bone

64 segment geometry (i.e. global anatomical adaptation), rather than by differences in

65 bone tissue properties (i.e. tissue-quality adaptation). A structure that is optimized for

66 a given loading condition presents a uniform state of stress: this corresponds at the

67 same time to a minimum amount of material (which translates into a minimal

68 metabolic energy expenditure, both during growth and during locomotion), and a

69 minimum risk of damage (Beer et al., 2006). However, the link between different 
70 dimensional scales (from tissue-scale local adaptation to organ-level optimal structure)

71 is far from understood.

72 The problem should then be considered at different dimensional scales. Rather than

73 sticking to the classic reductionist strategy, an integrative approach has recently been

74 proposed, which is capable to provide a deeper understanding (Noble, 2006). It has

75 been demonstrated that a synergic use of numerical models and in vitro simulations

76 (Cristofolini et al., 2010b) can provide the most reliable and extensive understanding

77 for such multiscale problems (Cristofolini et al., 2008; McDonald et al., 2010; Webster

78 and Muller, 2011).

79 This paper will review the evidence coming from in vitro testing concerning the 80 following questions:

81 - Are bones optimized in their multiscale structure?

82 - How does the structure of bones respond to the different "design 83 specifications"?

84 2. "IF BONE IS THE ANSWER, THEN WHAT IS THE QUESTION?" 85 (Huiskes, 2000)

86 Prof. Rik Huiskes certainly knew how to be provocative, and probably he actually

87 enjoyed fierce debates with colleagues, both at conferences and in scientific papers

88 (Huiskes, 1995, 2000). Myself, like many others who work in bone biomechanics,

89 was inspired by the work of prof. Huiskes, and, like him, tried to understand better

90 how and why bone adapts itself. Most of the work of prof. Huiskes and his co-workers

91 in the Eighties and Nineties turned around total hip replacement, rather than focusing

92 directly on bone. I suspect that he saw hip stems as a tool to "interrogate" the bone by 
93 modifying the loading imposed to the proximal femur, so that the laws of bone

94 adaptation could be investigated. In fact, in the last decade his activity was more

95 characterized by investigation on the bone in itself, including ageing, osteoporosis,

96 fatigue (Isaksson et al., 2006, 2008; Ruimerman et al., 2005a; van Oers et al., 2008;

97 van Oers et al., 2011), and more in general on the mechano-biology of bone adaptation

98 (van der Meulen and Huiskes, 2002).

\section{3. OPTIMIZATION OF THE PROXIMAL HUMAN FEMUR}

\section{1 "Design requirements"}

101 One frequently addressed example of structural optimization is the proximal human

102 femur. If one had to describe it in engineering design terms, these are the main 103 mechanical requirements:

104 - Provide a rigid structure for the attachment of muscles, ligaments and tendons,

105 which enables enable body movements.

106 - Effectively respond to physiological loads: daily loads applied to the femoral 107 head are cyclic by nature, and vary in direction (Bergmann, 2013). To resist 108 them effectively, a combination of cortical and trabecular bone is arranged so 109 as to provide the maximal fracture load with a minimal (but optimally 110 arranged) amount of bone material. No sort of failure (other than bone111 adaptation-inducing microcracks (Martin and Burr, 1982; Taylor and 112 Prendergast, 1997)) is acceptable, due to the cyclic nature of such loads. The 113 concept here is similar to the one that structural engineers apply to the design 114 of strenuously loaded mechanical components such as a crankshaft. 
- Safely resist to occasional trauma: a sideways fall is a common challenge to the proximal femur (Grisso et al., 1991; Hwang et al., 2011; Michelson et al., 1995; WHO, 1994, 2007). In this perspective, what really matters is toughness, i.e. the amount of energy absorbed prior to catastrophic failure. Sub-critical structural damage (partial bone fracture) is not desirable, but acceptable under these special circumstances. The concept here is similar to the principle that engineers apply to the design of car safety components such as the bumpers.

- Meet the requirements above with a minimal mass.

\subsection{Response to loading in a physiological direction}

124 As far as physiological loading of the femur is concerned, most of the published in

125 vitro studies focussed on the effect of hip stems (Cristofolini, 1997). Failure of the

126 proximal femoral metaphysis has often been investigated in vitro (e.g.: (Cristofolini et

127 al., 2007; Lochmüller et al., 2002; Yang et al., 1996)), but the strain distribution has

128 seldom been assessed. A theoretical study has shown that the shape and anteversion of

129 the femoral neck provides an optimal response to physiological loads (Fabeck et al.,

130 2002). The strain distribution in the intact and resurfaced femur has often been

131 investigated for a single loading configuration (Crick et al., 1985; Field and Rushton,

132 1989). However, the directions of the hip joint resultant force during physiological

133 and para-physiological motor tasks spans a cone of approximately $24^{\circ}$ (Bergmann,

134 2013). This certainly results in a variety of loading conditions in the femur (Duda et

135 al., 1998; Fabeck et al., 2002; Raftopoulos and Qassem, 1987; Rybicki et al., 1971).

136 Recently, the strain distribution (magnitude and direction of principal strains) in the

137 proximal femur has been measured by means of triaxial strain gauges at 12 locations 
138 (Cristofolini et al., 2009), with a number of loading scenarios spanning such a cone of

139 loading directions.

140 When physiological tasks are adequately simulated in vitro, the principal tensile strains

141 are comparable to those recorded in vivo (Table 1). Such values are also comparable

142 to the accepted threshold for physiological strain to prevent bone remodelling and 143 resorption.

144 Where principal tensile strain predominates in the femoral neck (supero-lateral side 145 during physiological loads), the cortical bone is thinner, whereas the cortex is thicker 146 in the areas where compression predominates (medial side) (Cristofolini et al., 2009).

147 This could be a strategy to minimize the risk of buckling.

148 When physiological loads are simulated in vitro, the direction of principal tensile strain 149 is generally aligned with the axis of the neck/diaphysis on the lateral and medial sides 150 (Cristofolini et al., 2009). This confirms the predominance of bending in the frontal 151 plane. Conversely, the direction of principal strains is generally close to $45^{\circ}$ from the 152 axis of the neck/diaphysis on the anterior and posterior sides (Cristofolini et al., 2009), 153 due to the presence of shear stress on the anterior and posterior sides, in agreement 154 with previous theoretical considerations (Fabeck et al., 2002). Such an alignment of 155 the principal strain directions is in agreement both with the reported trabecular 156 arrangement (Ciarelli et al., 1991; Huiskes et al., 2000; Ruimerman et al., 2005b; 157 Singh et al., 1970), and with the alignment of the osteons on the cortical surface (Baca 158 et al., 2007).

159 Not surprisingly, the magnitude of the principal strains vary significantly between the 160 different loading configurations within the $24^{\circ}$ cone mentioned above (Cristofolini et 161 al., 2009). However, the direction of principal strains in the cortical bone vary by a 
162 remarkably narrow angle (less than $+/-6^{\circ}$ ) when the hip joint force spans the $24^{\circ}$ cone 163 covered by physiological loading (Cristofolini et al., 2009). Hence, the state of stress

164 in the proximal metaphysis allows structural optimization to face most physiological 165 tasks: in fact, at each point it is sufficient if the materials has a single strongest 166 direction, to resist a range of loading directions. This architecture provides the 167 maximal strength for a range of loading directions: therefore the structural 168 optimization is robust with respect to a range of loading conditions (Anonymous, 169 2013b). These findings are in agreement with a continuum-model study (Pidaparti and 170 Turner, 1997), which demonstrated that a non-strictly-orthogonal trabecular 171 arrangement provides a mechanical advantage for multidirectional loading. This effect 172 can be achieved by a multiscale arrangement of the anisotropic and inhomogeneous 173 properties of the proximal femur, which generates a sort of "funnel effect" (Fig. 1).

174 The proximal femur is structurally optimized to withstand daily loads to such an extent 175 that any artificial modification of its structure makes it weaker. Insertion of a metal 176 component such as a resurfacing or a minimally invasive hip stem (definitely stronger 177 than bone) in the best case does not affect bone strength, but in the worst case can 178 significantly weaken the structure (Cristofolini et al., 2011; Davis et al., 2007; Long et 179 al., 2009; Morlock et al., 2006; Murray et al., 2007; Schlegel et al., 2010).

180 The so-called spontaneous fractures (Jeffery, 1974; Michelson et al., 1995) can occur 181 in a specific type of subjects (Viceconti et al., 2012) when an excessive force is 182 applied to the proximal femur in a physiological direction (e.g. simulating stance). If 183 this scenario is replicated in vitro, the femur exhibits an almost-perfectly elastic 184 response (Juszczyk et al., 2011), with minimal delay between fracture onset and 185 catastrophic failure (Juszczyk et al., 2013) (Fig. 2). Such a brittle behaviour is typical 186 of materials and structures where the largest possible failure force is achieved, while 
187 giving up ductility. Therefore the femur seems to be optimized to withstand the largest

188 possible force peak (and hence the largest fatigue-inducing cyclic load) during 189 physiological loading.

190 Recently, a study was carried out on the safety factor of the proximal femur of a 191 diverse population (200 subjects, male and female, 23 to 84 years old (Taddei et al., IN 192 PRESS)). Subject-specific FE models were built using a multi-scale approach that 193 incorporated inhomogeneous tissue properties, and scaled musculo-skeletal loads. 194 This study has shown that the proximal femur has a remarkably constant safety factor 195 with respect to a wide range of loading directions experienced during physiological 196 activities.

\section{$197 \quad 3.3$ Response to loading in a non-physiological direction}

198 Most fractures in the proximal femoral metaphysis are a consequence of accidental 199 falls (Hayes et al., 1993; Parkkari et al., 1999). There is a general agreement on the 200 mechanism leading to fractures in the proximal femur during falls: in most cases the 201 subject falls on his/her side hitting the floor with the side of the hip (Nankaku et al., 202 2005; van den Kroonenberg et al., 1996). As a consequence, a force is delivered to the 203 greater trochanter through the soft tissues, which is more or less perpendicular to the 204 long axis of the femur (Hayes et al., 1993; Parkkari et al., 1999). At the same time, 205 part of the load is transmitted from the pelvis to the femoral head. This scenario loads 206 the proximal femur with a large bending moment in the frontal plane, having opposite 207 direction to the physiological one (and possibly a torsional moment). No information 208 is available about the exact direction of the forces applied during a sideways fall (in 209 fact, falling itself is an unpredictable event). 
210 The first in vitro simulation of sideways fall loading of the femur is due to Backman

211 (Backman, 1957): the femur diaphysis (adducted by $10^{\circ}$, internally rotated by $15^{\circ}$ ) was

212 held distally, free to rotate in the frontal plane, while a force was applied to the femoral

213 head with the greater trochanter resting on a clay cushion.

214 The failure force of the proximal femur has often been measured under in vitro

215 simulated sideways fall (Bauer et al., 2006; Bouxsein et al., 1999; Cheng et al., 1997;

216 Courtney et al., 1994; Eckstein et al., 2002; Eckstein et al., 2004; Juszczyk et al.,

217 2010). The strain distribution in the proximal femur has also been measured in vitro

218 for a simulated fall (a sideways load was delivered to a femur adducted and internally

219 rotated by $30^{\circ}$, while strain was measured at 9 locations (Lotz et al., 1991)). More

220 recently, an in vitro test has been developed that enables measuring the strain

221 distribution in the proximal femur for a simulated sideways fall where a wide range of

222 loading adduction and internal rotation angles can be explored (Zani et al., 2014).

223 Also for this kind of loading, the magnitude of principal strains strongly depends on

224 the direction of the applied force (Cristofolini, 2011; Zani et al., 2012; Zani et al., 225 SUBMITTED). Increasing the internal rotation angle (and consequently, the bending 226 moment in the neck and the torque delivered to the proximal diaphysis) a general 227 increase of strains was observed. The largest compressive strain are found on the 228 supero-lateral neck region, and are more than double of the largest tensile strain (on 229 the medial side). This tends to crush the thin cortical shell and trabeculae that are 230 present on the supero-lateral side (such a structure represents an optimum only for a 231 physiological loading scenario, which generates tension in this region). For this 232 reason, failure can initiate due to compression, in the supero-lateral neck region 233 (Cristofolini, 2011; de Bakker et al., 2009; Zani et al., 2012; Zani et al., 2014; Zani et 
234 al., SUBMITTED). Furthermore, fracture is not achieved as a single catastrophic

235 event, but takes energy and time to occur (Fig. 2).

236 The force required to fracture a femur in a sideways fall is lower than for physiological

237 loading directions by a factor that varies between 2.16 according to an in vitro study

238 (Keyak, 2000), 2.85 according to a FE study (Keyak et al., 2001), 3.5 according to a

239 different in vitro study (Duchemin et al., 2006), and 4.4 according to a more recent FE

240 study (Bessho et al., 2009). Conversely, the energy required to fracture a femur in

241 sideways fall is 1.4 times higher than for physiological loading directions (Duchemin

242 et al., 2006).

243 For a simulated sideways fall, the direction of principal strains varied greatly (by up to

$24445^{\circ}$ ) when the loading direction was tilted within a $30^{\circ}$ cone (Cristofolini, 2011; Zani

245 et al., 2012). The largest variations in alignment were observed on the lateral side.

246 This is quite different from what occurs for physiological loading, where the direction

247 of the applied force has a minimal effect of the alignment of principal strains, and can

248 be taken as an indicator of the fact that principal strains go "against" the strongest

249 directions of the anisotropic bone tissue. For this reason, the "funnel effect" described

250 above does not work when a force is applied laterally (Fig. 1).

\section{$251 \quad 3.4$ The optimized femur}

252 As previously reported, the need for optimizing the femur for cyclic daily loads

253 requires a stiff structure, with spatial constraints that results in a vulnerable structure 254 when a different load is applied, such as during a fall (Currey, 2003). However, 255 evolution has lead to a structure that is optimized to different scenarios (Fig. 2): when 256 daily loads are exerted, the proximal femur is rigid (providing maximal efficiency) and 257 strong (preventing excessive propagation of fatigue cracks). If an occasional overload 
258 is applied during a fall, the maximal force is lower, but the proximal femur undergoes

259 a quite progressive failure, which enables absorbing a much higher energy before

260 complete failure.

\section{4. OPTIMIZATION OF THE DIAPHYSIS OF THE HUMAN TIBIA}

\section{$262 \quad 4.1$ Anatomical and biomechanical considerations}

263 The human tibia shows a peculiar shape when observed from lateral, where its cross-

264 section varies linearly along its axis (Fig. 3). This suggests that the shape of the tibia

265 could be optimized to resist cantilever load acting in the sagittal plane. In fact, when a

266 slender structure is loaded by a shear force, a compressive force, and a bending

267 moment, the latter generates stress values that can be orders of magnitude higher (and

268 at a higher risk of fracture) that the other load components (Beer et al., 2006).

269 There are some anatomical peculiarities that should be considered for the tibia: first of

270 all, there is no major muscle insertion in a large portion of the diaphysis; the main

271 proximal insertion is that of the patellar tendon. Furthermore, the two main joint

272 complexes (i.e. knee and ankle) can be, as a first approximation, considered

273 respectively as a cylindrical hinge and a saddle. From these considerations, it is likely

274 that a compressive force is transmitted through the tibial plateau (which is relatively

275 flat), while a moment is generated in the sagittal plane by the patellar tendon.

276 Equilibrium is achieved by the ankle joint reaction. This consideration is confirmed by

277 musculoskeletal models (Wehner et al., 2009), and by in vivo measurements of joint

278 forces by means of knee prostheses for a number of physiological activities (gait, stair-

279 climbing and -descending, jogging (Bergmann, 2013; Kutzner et al., 2010;

280 Mundermann et al., 2008)): 
- The largest component of force is directed axially, while the second largest component of force is the antero-posterior one (one order of magnitude lower than the axial one). The right-left force component is 2-10 times lower than the antero-posterior one.

- When the force peak is reached, the moment in the sagittal plane is at least twice as high as the moment in the frontal plane. The torsional moment about the tibial axis is lower in magnitude than the other two moments.

288 Given this relatively simple loading condition, one could expect the anatomy of the 289 human tibia to generate a uniform state of stress, which would correspond to an 290 optimized organ-level structure (Beer et al., 2006). The geometric moments of area 291 (where the cross-section was modelled as a homogenous, hollow axisymmetric shaft) 292 exhibit an almost-linear variation along the tibia (Martens et al., 1981; Minns et al., 293 1975).

294 A recent study where six cadaver tibias were CT scanned (Cristofolini et al., 2013a) 295 has shown that the diaphysis of the tibia is shaped so as to resist best to a linearly296 varying bending moment in the sagittal plane, such as for cantilever loading 297 (Cristofolini et al., 2013a):

298 - The moments of area and moments of inertia increased linearly from distal to 299 proximal.

300 - Linearity was stronger for the area and inertia properties corresponding to a 301 moment in the sagittal plane than in the frontal one.

302 - The section modules increased linearly from distal to proximal. 
- Conversely, the variations of area and polar moments along the tibia did not seem to be optimized for the corresponding loading components (torsion and axial force).

\subsection{Strain distribution}

307 In vivo strain has been measured in the human tibia. However, such experiments are 308 limited by the number of strain measurement locations (typically just one point) (Al 309 Nazer et al., 2012). Therefore, the strain distribution in vivo is not known. In vitro 310 strain measurements in the human tibia concentrated on four-point-bending, axial 311 compression and torsion (Cristofolini et al., 2010a; Cristofolini and Viceconti, 2000;

312 Gray et al., 2008; Gray et al., 2007; Heiner, 2008).

313 An in vitro study on six tibias, each with 28 triaxial strain gauges, investigated the 314 hypothesis that the strain distribution in the human tibia is optimized for a cantilever 315 loading in the sagittal plane (Cristofolini et al., 2013a). The strain distribution for the 316 different loading configurations showed that the diaphysis of the tibia behaves as a 317 uniform-stress structure (i.e. optimized (Beer et al., 2006)) for a cantilever loading in 318 the sagittal plane and, to a lesser extent, in the frontal plane (Fig. 4). In fact, the strain 319 distribution was remarkably uniform along the tibia for cantilever loading. For all the 320 other loading configurations (including axial compression), the strain variations along 321 the tibia were one order of magnitude larger than for cantilever.

\section{$322 \quad$ 4.3 The optimized tibia}

323 In conclusion, the in vitro studies mentioned above support the idea that the human 324 tibia is optimized to resists to the bending moment that is generated in the sagittal 325 plane when a force is delivered to its distal extremity (with an antero-posterior 
326 component). In fact, such a force generates a bending moment that varies linearly

327 along the diaphysis. Such a linearly-varying bending moment is compensated by a

328 linear variation of the cross-sectional properties along the tibia. This results in a 329 remarkably uniform state of stress in the diaphysis, which is a highly efficient 330 structural solution.

331 5. OPTIMIZATION OF THE BODY OF THE THORACOLUMBAR 332 VERTEBRAE

\section{$333 \quad 5.1$ Anatomical and biomechanical considerations}

334 Daily activity induces complex loading scenarios on the human vertebrae. Information

335 about spinal loads can be derived from a combination of in vivo measured kinematic

336 parameters and mathematical models. A similar approach has been used to predict 337 compressive forces and moments in the lumbar spine during lifting activities (Dolan et 338 al., 1994). EMG-based techniques, along with intra-discal pressure measurements, 339 have been used to validate biomechanical models for the prediction of spinal loads 340 (Hansson et al., 1984; Schultz et al., 1982). While biomechanical simulations have the 341 advantage of being non-invasive, more reliable loading data can only be obtained 342 through direct in vivo measurement with telemeterized spinal implants (Ledet et al., 343 2012). An extensive amount of spinal load data is available for different motor tasks 344 and postoperative periods (Bergmann, 2013). From the analysis above it is clear that 345 only indicative estimates of the loads (and their direction) acting on the vertebrae in 346 vivo is possible.

347 From the analysis of the spine models and in vivo data, one can conclude that 348 (Brandolini et al., 2014): 
- During physiological loading, the intervertebral disks in first approximation act ball-joint-like structures. Such a hypothesis underlies many numerical models

357 The optimal structure to withstand a distributed force consists of a dense mesh of 358 cancellous bone (with the trabeculae being aligned with the axial force itself), and an 359 extremely thin cortical shell (Fields et al., 2011; Prakash et al., 2007).

\section{$360 \quad 5.2$ Strain distribution}

361 One of the first studies on the strain distribution in the vertebral body was carried out 362 by means of brittle coating, photoelasticity (Shah et al., 1976) and 17 strain gauges 363 (Shah et al., 1978), for different compressive loads. They reported strains of the order 364 of 500-1500 microstrains for a $1470 \mathrm{~N}$ compressive force. The effect of an inclined 365 load $\left(2800 \mathrm{~N}\right.$ at $\left.16^{\circ}\right)$ has been investigated on functional spinal units using 3 to 4 strain 366 gauges, where compressive strain of about 650 microstrain were measured (Lin et al.,

367 1978). Strains induced by compression and shear loads were quantified with three 368 triaxial strain gauges on the vertebral rim, and one on the endplate surface (Frei et al., 369 2002). Fracture risk was assessed by (Kayanja et al., 2004), but the most stressed 370 region could not be identified as only one gauge was applied on each vertebral body. 371 Axial compression is probably the most frequent in vitro loading condition (e.g. 
372 (Bürklein et al., 2001; Fields et al., 2011; Jiang et al., 2010; Lochmüller et al., 2008;

373 Luo et al., 2010)). In some cases also eccentric compression (Furtado et al., 2007; Teo

374 et al., 2001) or anterior bending (Buckley et al., 2007; Granhed et al., 1989) were

375 simulated. Recently, a study was published (Cristofolini et al., 2013b) where eight

376 thoracolumbar vertebrae instrumented with eight triaxial strain gauges. The vertebrae

377 were loaded through their disks and were subjected to a variety of loading conditions

378 that included the cone spanned by the resultant force during physiological motor tasks,

379 but also other load components such as torsion and traction (Bergmann, 2013). The

380 principal strains were generally aligned as expected: axially/circumferentially for all

381 loading configurations implying a compressive force, and roughly at $45^{\circ}$ for torsion.

382 The results from (Cristofolini et al., 2013b) indicate that the structure of the vertebral

383 body is optimized for a compressive force aligned with the vertebral body. In fact:

384 - Strain was lower when the compressive force is perpendicular to the vertebral 385 body, as opposed to all the configurations where the force was tilted by $15^{\circ}$ in 386 any direction within the $30^{\circ}$ cone (Fig. 5).

- The strain distribution was significantly more uniform for axial-compression than for any other configuration (Fig. 5): uniform stress/strain is an optimization criterion in structural engineering (Beer et al., 2006).

- When the force was tilted by $15^{\circ}$ in any direction, the direction of principal strains varies by a much wider angle (nearly $30^{\circ}$ ) compared to the axialcompression configuration (Fig. 6). As bone (especially trabecular bone) is known to be significantly weaker when loaded oblique to its structure (Fields et al., 2011; Öhman et al., 2007), this seems to suggest that the structure of the vertebra is optimized (in terms of local tissue arrangement, and anisotropy) for a single, specific, loading direction. 


\subsection{The optimized vertebral body}

398 The studies above concur on the idea that the micro- and macro-structure of the 399 vertebral body is optimized to withstand the daily loads: a distributed force strongly

400 aligned with the vertebral body itself. Any other load, different from the ones for 401 which the structure is optimized, is not resisted as effectively (Fig. 5,6): for instance, 402 when a bending moment or an eccentric force are applied, the strength of the vertebra 403 is significantly lower than for a purely axial force (Buckley et al., 2007; Bürklein et al., 404 2001; Fields et al., 2011; Kayanja et al., 2004; Teo et al., 2001). In fact, a 405 modification to such an optimized structure may results in a weakening of the structure 406 itself. This could be the reason for the contradictory results reported for prophylactic 407 vertebroplasty (Cristofolini et al., 2013c; Cristofolini et al., SUBMITTED; Oakland et 408 al., 2009).

409 It must be pointed out that such a structure of the vertebral body is optimal for biped 410 locomotion, where the spine mainly works in compression (i.e. in humans and 411 primates (Sheng et al., 2009)). Conversely, the spine in quadrupeds is mostly 412 subjected to bending. The optimal structure in that case is more similar to that of the 413 diaphysis of long bones: a hollow, thick cortical shell filled with a coarse trabecular 414 structure (Boszczyk et al., 2001; Kandziora et al., 2001; Sheng et al., 2009).

\section{6. CONCLUSIONS ("SURVIVAL” IS THE QUESTION)}

416 The examples in the previous pages show how bones are optimized structures in a very

417 complex way. In fact: (i) they are able to withstand daily loads with a rather uniform 418 margin of safety; (ii) they are able to tolerate variations of direction of such daily 419 loads, without loosing such an optimal distribution of stress/strain; (iii) they do so with 
420 a minimal mass; (iv) they are sufficiently tough to minimize damage when an 421 occasional non-physiological load occurs. The first three criteria are rewarded in daily 422 life (in terms of minimal expenditure of resources), and could be driven by a daily 423 stimulus. Conversely, the fourth criterion becomes crucial only occasionally (in terms 424 of survival to trauma), and cannot be based on a stimulus on a daily basis.

425 To make things more complex, one should not forget the additional challenge posed by 426 growth: in fact, the structure needs to be optimized throughout increase in size. This is 427 possibly accounted for by the fact that bones are not just "designed and built", but they 428 grow and adapt over an entire lifetime.

429 At the tissue-level, biological studies have uncontrovertibly shown that bone tissue 430 responds to mechanical loads with a local deposition/resorption balance in a way that 431 tends to generate a uniform state of stress. This means that bone tissue is capable of 432 adapting to the mechanical demand (and to changes of the mechanical demand) at each 433 anatomical site of each individual. However, local optimization (at the tissue-level) 434 does not automatically guarantee structural optimization (at the organ-level). The 435 shape-function relationship of bones is a debated issue. No mechanism for an "active" 436 global structural optimization has so far been identified within the bone metabolism.

437 The overall "engine" behind such efficient, safe and robust structural arrangement of 438 skeletal bones is evolution. The best phenotype variations (either deriving from gene 439 mutations, or from mutation-driven changes in gene regulation and expression) tend to 440 procreate; sub-optimal variations tend to be lost (too heavy and slow to escape a 441 predator, or whining in a ditch with a broken bone). This mechanism acts at (at least) 442 two levels: 
1. The overall optimal anatomy (e.g. number of bones, their mutual position, their gross geometry) has been selected through the generations. The recent evolutionary developmental biology approach (EVO-DEVO (Anonymous, 2013a)) suggests that modularity is a key pattern in the evolution process.

2. At the same time, a mechanism for on-the-fly adaptation has been selected and embedded in the form of mechanically-regulated deposition-resorption mechanisms, that is capable of adjusting the local structure in response to an altered mechanical environment. This is a necessary adaptation mechanism as there is no "optimal structure" that fits all individuals, all lifestyles, and all stages of life (Jepsen, 2011).

453 To describe it with a metaphor: in order to fly, an aircraft needs to have a suitable 454 structure (wings, vertical stabilizer, rudder, flaps, etc), but also the ability to adjust 455 dynamically its elements in order to remain stable.

456 To follow up Prof. Huiskes provocation ("If bone is the answer, then what is the 457 question?" (Huiskes, 2000)), this review suggests that the question to which bone is 458 the answer remains "how to best survive?".

\section{Acknowledgments}

460 The Author wishes to acknowledge the contribution of a number of colleagues and co461 skilled workers from Bologna that in these 20 years contributed to the gathering and 462 understanding of a large amount of in vitro data. The Author wishes to acknowledge 463 Marco Viceconti, for many years of stimulating collaboration, which is the background 464 of this paper. Thanks to Luigi Lena and Federica Caffagni for the artwork. This study

465 was funded by the European Community Seventh Framework Programme ("The 
466 Osteoporotic Virtual Physiological Human-VPHOP” Grant FP7- ICT2008-223865, 467 and "MXL", Grant ICT-2009.5.2 248693), and by the Italian Ministry of Education 468 (PRIN 2010-11, Grant 2010R277FT "Fall risk estimation and prevention in the elderly 469 using a quantitative multifactorial approach"). 


\section{REFERENCES:}

Aamodt, A., Lund-Larsen, J., Eine, J., Andersen, E., Benum, P., Husby, O.S., 1997. In vivo measurements show tensile axial strain in the proximal lateral aspect of the human femur. J Orthop Res. 15, 927-931.

Al Nazer, R., Lanovaz, J., Kawalilak, C., Johnston, J.D., Kontulainen, S., 2012. Direct in vivo strain measurements in human bone-a systematic literature review. J Biomech 45, 27-40.

Anonymous, 2013a. "Evolutionary developmental biology" http://en.wikipedia.org/wiki/Evo_devo interrogated on 12 December 2013. Wikipedia.

Anonymous, 2013b. "Robust Optimization", http://en.wikipedia.org/wiki/Robust_optimization interrogated on 24 November 2013.

Baca, V., Kachlik, D., Horak, Z., Stingl, J., 2007. The course of osteons in the compact bone of the human proximal femur with clinical and biomechanical significance. Surg Radiol Anat 29, 201-207.

Backman, S., 1957. The proximal end of the femur: investigations with special reference to the etiology of femoral neck fractures; anatomical studies; roentgen projections; theoretical stress calculations; experimental production of fractures. Acta Radiol Suppl, 1-166.

Bauer, J.S., Kohlmann, S., Eckstein, F., Mueller, D., Lochmuller, E.M., Link, T.M., 2006. Structural analysis of trabecular bone of the proximal femur using multislice computed tomography: a comparison with dual X-ray absorptiometry for predicting biomechanical strength in vitro. Calcif Tissue Int 78, 78-89.

Bayraktar, H.H., Morgan, E.F., Niebur, G.L., Morris, G.E., Wong, E.K., Keaveny, T.M., 2004. Comparison of the elastic and yield properties of human femoral trabecular and cortical bone tissue. J Biomech 37, 27-35.

Beer, F.P., Johnston, E.R.J., DeWolf, J.T., 2006. Mechanics of mateirals (4th edition). McGraw-Hill, Boston.

Bergmann, G., 2013. (ed.), Charite - Universitaetsmedizin Berlin "OrthoLoad". Retrieved November 1, 2013. <http://www.OrthoLoad.com>.

Bertram, J.E.A., Swartz, S.M., 1991. The law of bone transformation: a case of crying wolff? Biol. Rev. 66, 245-273.

Bessho, M., Ohnishi, I., Matsumoto, T., Ohashi, S., Matsuyama, J., Tobita, K., Kaneko, M., Nakamura, K., 2009. Prediction of proximal femur strength using a CT-based nonlinear finite element method: differences in predicted fracture load and site with changing load and boundary conditions. Bone 45, 226-231.

Boszczyk, B.M., Boszczyk, A.A., Putz, R., 2001. Comparative and functional anatomy of the mammalian lumbar spine. Anat Rec 264, 157-168.

Bouxsein, M.L., Coan, B.S., Lee, S.C., 1999. Prediction of the strength of the elderly proximal femur by bone mineral density and quantitative ultrasound measurements of the heel and tibia. Bone 25, 49-54. 
Brandolini, N., Cristofolini, L., Viceconti, M., 2014. Experimental methods for the biomechanical investigation of the human spine: a review Journal of Mechanics in Medicine and Biology 14, 1430002 (1430033 pages).

Buckley, J.M., Cheng, L., Loo, K., Slyfield, C., Xu, Z., 2007. Quantitative Computed Tomography-Based Predictions of Vertebral Strength in Anterior Bending. Spine 32, 10191027.

Bürklein, D., Lochmüller, E.M., Kuhn, V., Grimm, J., Barkmann, R., Müller, R., Eckstein, F., 2001. Correlation of thoracic and lumbar vertebral failure loads with in situ vs. ex situ dual energy X-ray absorptiometry. Journal of Biomechanics 34, 579-587.

Carter, D.R., 1984. Mechanical loading histories and cortical bone remodeling. Calcif Tissue Int 36 Suppl 1, S19-24.

Cheng, X.G., Lowet, G., Boonen, S., Nicholson, P.H., Brys, P., Nijs, J., Dequeker, J., 1997. Assessment of the strength of proximal femur in vitro: relationship to femoral bone mineral density and femoral geometry. Bone 20, 213-218.

Ciarelli, M.J., Goldstein, S.A., Kuhn, J.L., Cody, D.D., Brown, M.B., 1991. Evaluation of orthogonal mechanical properties and density of human trabecular bone from the major metaphyseal regions with materials testing and computed tomography. J Orthop Res. 9, 674682.

Courtney, A.C., Wachtel, E.F., Myers, E.R., Hayes, W.C., 1994. Effects of loading rate on strength of the proximal femur. Calcified Tissue International 55, 53-58.

Cowin, S.C., 2001. Bone Mechanics Handbook. CRC Press.

Crick, D., Wagner, J., Bourgois, R., Dehu, P., 1985. Comportement mécanique de l'épiphyse supérieure de fémur resurfacé et incidence des variations anatomiques et des différentes types de cupules. Acta Orthop. Belg. 51, 168-178.

Cristofolini, L., 1997. A critical analysis of stress shielding evaluation of hip prostheses. Crit Rev Biomed Eng 25, 409-483.

Cristofolini, L., Year Is the proxinal femur optimized? For what loading scenario? In Engineers and Surgeons: Joined at the hip III Event proceedings, IMechE Publ: 3-9.

Cristofolini, L., Angeli, E., Juszczyk, J.M., Juszczyk, M.M., 2013a. Shape and function of the diaphysis of the human tibia. J Biomech 46, 1882-1892.

Cristofolini, L., Baleani, M., Schileo, E., Van Sint Jan, S., Juszczyk, M.M., Öhman, C., I., Z., Lefèvre, P., Juszczyk, J.M., Viceconti, M., 2014. Differences between contralateral bones of the human lower limbs: a multiscale investigation. Journal of Mechanics in Medicine and Biology 14, 1450032 (1450028 pages).

Cristofolini, L., Brandolini, N., Danesi, V., Juszczyk, M.M., Erani, P., Viceconti, M., $2013 b$. Strain distribution in the lumbar vertebrae under different loading configurations. The Spine Journal 13, 1281-1292.

Cristofolini, L., Conti, G., Juszczyk, M., Cremonini, S., Van Sint Jan, S., Viceconti, M., 2010a. Structural behaviour and strain distribution of the long bones of the human lower limbs. J Biomechanics 43, 826-835.

Cristofolini, L., Ferguson, S.J., Brandolini, N., Danesi, V., Juszczyk, M.M., Year Biomechanical investigation of augmentation in the lumbar vertebrae. In Proceedings of the 
19th Congress of the European Society of Biomechanics CD, University of Patras Publ.: paper \#SO7.2-082.

Cristofolini, L., Ferguson, S.J., Danesi, V., Erani, P., Viceconti, M., Brandolini, N., SUBMITTED. Biomechanical effectiveness of prophylactic augmentation: an in vitro study. Clin Biomech (Bristol, Avon).

Cristofolini, L., Juszczyk, M., Martelli, S., Taddei, F., Viceconti, M., 2007. In vitro replication of spontaneous fractures of the proximal human femur. J Biomech 40, 2837-2845.

Cristofolini, L., Juszczyk, M., Taddei, F., Field, R.E., Rushton, N., Viceconti, M., 2011. Assessment of femoral neck fracture risk for a novel proximal epiphyseal hip prosthesis. Clin Biomech (Bristol, Avon) 26, 585-591.

Cristofolini, L., Juszczyk, M., Taddei, F., Viceconti, M., 2009. Strain distribution in the proximal human femoral metaphysis. Proc Inst Mech Eng [H] 223, 273-288.

Cristofolini, L., Schileo, E., Juszczyk, M., Taddei, F., Martelli, S., Viceconti, M., 2010b. Mechanical testing of bones: the positive synergy of FE models and in vitro experiments. Philos Transact A Math Phys Eng Sci 368, 2725-2763.

Cristofolini, L., Taddei, F., Baleani, M., Baruffaldi, F., Stea, S., Viceconti, M., 2008. Multiscale investigation of the functional properties of the human femur. Philos Transact A Math Phys Eng Sci 366, 3319-3341.

Cristofolini, L., Viceconti, M., 2000. Mechanical validation of whole bone composite tibia models. J Biomech 33, 279-288.

Crystal, D., 1998. "Culmann, Karl (1821-1881)" The Cambridge Biographical Encyclopedia (2nd ed.) Cambridge University Press, Cambridge, England, ISBN 0-521-63099-1.

Currey, J.D., 1982. Bone as a mechanical structure, in: Huiskes, R., van Campen, D.H., de Wijn, J.R. (Eds.), Biomechanics - Principles and applications. Martinus Nijhoff Publishers, pp. 75-85.

Currey, J.D., 2003. How well are bones designed to resist fracture? J Bone Miner Res 18, 591598.

Davis, E.T., Olsen, M., Zdero, R., Waddell, J.P., Schemitsch, E.H., Year The effect of femoral component alignment on the risk of femoral neck fracture following hip resurfacing. In IMechE Conference: Engineers \& Surgeons: joined at the hip. London.

de Bakker, P.M., Manske, S.L., Ebacher, V., Oxland, T.R., Cripton, P.A., Guy, P., 2009. During sideways falls proximal femur fractures initiate in the superolateral cortex: evidence from high-speed video of simulated fractures. J Biomech 42, 1917-1925.

de Zee, M., Hansen, L., Wong, C., Rasmussen, J., Simonsen, E.B., 2007. A generic detailed rigid-body lumbar spine model. J Biomech 40, 1219-1227.

Demes, B., 2007. In vivo bone strain and bone functional adaptation. American Journal of Physical Anthropology 133, 717-722.

Dolan, P., Earley, M., Adams, M.A., 1994. Bending and compressive stresses acting on the lumbar spine during lifting activities. J Biomech 27, 1237-1248.

Duchemin, L., Skalli, W., Topouchian, V., Benissa, M., Mitton, D., Year Femoral fracture load and failure energy in two load configurations: an in vitro study. In 16th EORS Annual meeting. Bologna. 
Duda, G.N., Heller, M., Albinger, J., Schulz, O., Schneider, E., Claes, L., 1998. Influence of muscle forces on femoral strain distribution. J Biomech. 31, 841-846.

Eckstein, F., Lochmuller, E.M., Lill, C.A., Kuhn, V., Schneider, E., Delling, G., Muller, R., 2002. Bone strength at clinically relevant sites displays substantial heterogeneity and is best predicted from site-specific bone densitometry. J Bone Miner Res 17, 162-171.

Eckstein, F., Wunderer, C., Boehm, H., Kuhn, V., Priemel, M., Link, T.M., Lochmüller, E.-M., 2004. Reproducibility and side differences of mechanical tests for determining the structural strength of the proximal femur. J. Bone and Mineral Research 19, 379-385.

Fabeck, L., Tolley, M., Rooze, M., Burny, F., 2002. Theoretical study of the decrease in the femoral neck anteversion during growth. Cells Tissues Organs 171, 269-275.

Field, R.E., Rushton, N., 1989. Proximal femoral surface strain gauge analysis of a new epiphyseal prosthesis. J. Biomed. Eng. 11, 123-129.

Fields, A.J., Lee, G.L., Liu, X.S., Jekir, M.G., Guo, X.E., Keaveny, T.M., 2011. Influence of vertical trabeculae on the compressive strength of the human vertebra. Journal of Bone \& Mineral Research 26, 263-269.

Frei, H., Oxland, T.R., Nolte, L.P., 2002. Thoracolumbar spine mechanics contrasted under compression and shear loading. J Orthop Res. 20, 1333-1338.

Fung, Y.C., 1980. Biomechanics - Mechanical properties of living tissues. Springer Verlag Publ., New York.

Furtado, N., Oakland, R.J., Wilcox, R.K., Hall, R.M., 2007. A Biomechanical Investigation of Vertebroplasty in Osteoporotic Compression Fractures and in Prophylactic Vertebral Reinforcement. Spine 32, E480-E487 410.1097/BRS.1090b1013e31811ea31812ee.

Granhed, H., Jonson, R., Hansson, T., 1989. Mineral content and strength of lumbar vertebrae. A cadaver study. Acta orthopaedica Scandinavica 60, 105-109.

Gray, H.A., Taddei, F., Zavatsky, A.B., Cristofolini, L., Gill, H.S., 2008. Experimental validation of a finite element model of a human cadaveric tibia. Journal of Biomechanical Engineering (ASME) 130, 031016.

Gray, H.A., Zavatsky, A.B., Taddei, F., Cristofolini, L., Gill, H.S., 2007. Experimental validation of a finite element model of a composite tibia. Proc Inst Mech Eng [H] 221, 315324.

Grisso, J.A., Kelsey, J.L., Strom, B.L., Chiu, G.Y., Maislin, G., O'Brien, L.A., Hoffman, S., Kaplan, F., 1991. Risk factors for falls as a cause of hip fracture in women. The Northeast Hip Fracture Study Group. N. Engl. J. Med. 324, 1326-1331.

Han, K.S., Zander, T., Taylor, W.R., Rohlmann, A., 2011. An enhanced and validated generic thoraco-lumbar spine model for prediction of muscle forces. Med Eng Phys 34, 709-716.

Hansson, T.H., Bigos, S.J., Wortley, M.K., Spengler, D.M., 1984. The load on the lumbar spine during isometric strength testing. Spine (Phila Pa 1976) 9, 720-724.

Hayes, W.C., Myers, E.R., Morris, J.N., Gerhart, T.N., Yett, H.S., Lipsitz, L.A., 1993. Impact near the hip dominates fracture risk in elderly nursing home residents who fall. Calcif Tissue Int 52, 192-198.

Heiner, A.D., 2008. Structural properties of fourth-generation composite femurs and tibias. J Biomech 41, 3282-3284. 
Huiskes, R., 1993. Stress shielding and bone resorption in THA: clinical versus computersimulation studies. Acta Orthop. Belg. 59, 118-129.

Huiskes, R., 1995. The law of adaptive bone remodeling: a case for crying Newton?, in: Odgaard, A., Weinans, H. (Eds.), Bone structure and remodeling (Recent advances in human biology - Volume 2). World Scientific, pp. 15-24.

Huiskes, R., 2000. If bone is the answer, then what is the question? Journal of anatomy 197 ( Pt 2), 145-156.

Huiskes, R., Ruimerman, R., van Lenthe, G.H., Janssen, J.D., 2000. Effects of mechanical forces on maintenance and adaptation of form in trabecular bone. Nature 405, 704-706.

Huiskes, R., Weinans, H., Dalstra, M., 1989. Adaptive bone remodeling and biomechanical design considerations for noncemented total hip arthroplasty. Orthopedics 12, 1255-1267.

Huiskes, R., Weinans, H., Grootenboer, H.J., Dalstra, M., Fudala, B., Sloof, T.J., 1987. Adaptive bone-remodeling theory applied to prosthetic-design analysis. J Biomech. 20, 11351150 .

Huiskes, R., Weinans, H., Van Rietbergen, B., 1992. The relationship between stress shielding and bone resorption around total hip stems and the effect of flexible materials. Clin Orthop Relat Res. 274, 124-134.

Hwang, H.F., Lee, H.D., Huang, H.H., Chen, C.Y., Lin, M.R., 2011. Fall mechanisms, bone strength, and hip fractures in elderly men and women in Taiwan. Osteoporos Int 22, 23852393.

Isaksson, H., van Donkelaar, C.C., Huiskes, R., Ito, K., 2006. Corroboration of mechanoregulatory algorithms for tissue differentiation during fracture healing: Comparison with in vivo results. J Orthop Res 24, 898-907.

Isaksson, H., van Donkelaar, C.C., Huiskes, R., Ito, K., 2008. A mechano-regulatory bonehealing model incorporating cell-phenotype specific activity. Journal of theoretical biology $252,230-246$.

Jeffery, C.C., 1974. Spontaneous fractures of the femoral neck. Orthop Clin North Am 5, 713 727.

Jepsen, K.J., 2011. Functional interactions among morphologic and tissue quality traits define bone quality. Clinical orthopaedics and related research 469, 2150-2159.

Jiang, G., Luo, J., Pollintine, P., Dolan, P., Adams, M.A., Eastell, R., 2010. Vertebral fractures in the elderly may not always be "osteoporotic". Bone 47, 111-116.

Juszczyk, M., Cristofolini, L., Kaniuk, J., Schileo, E., Viceconti, M., 2010. A novel method for determining the time and location of abrupt fracture initiation in bones. J. Strain Analysis in Engineering Design 45, 481-493.

Juszczyk, M.M., Cristofolini, L., Salvà, M., Zani, L., Schileo, E., Viceconti, M., 2013. Accurate in vitro identification of fracture onset in bones: Failure mechanism of the proximal human femur. J Biomechanics 46, 158-164.

Juszczyk, M.M., Cristofolini, L., Viceconti, M., 2011. The human proximal femur behaves linearly elastic up to failure. J Biomech 44, 2259-2266. 
Kandziora, F., Pflugmacher, R., Scholz, M., Schnake, K., Lucke, M., Schroder, R., Mittlmeier, T., 2001. Comparison between sheep and human cervical spines: an anatomic, radiographic, bone mineral density, and biomechanical study. Spine (Phila Pa 1976) 26, 1028-1037.

Kayanja, M.M., Ferrara, L.A., Lieberman, I.H., 2004. Distribution of anterior cortical shear strain after a thoracic wedge compression fracture. The Spine Journal 4, 76-87.

Keyak, J.H., 2000. Relationships between femoral fracture loads for two load configurations. J Biomech. 33, 499-502.

Keyak, J.H., Skinner, H.B., Fleming, J.A., 2001. Effect of force direction on femoral fracture load for two types of loading conditions. J Orthop Res 19, 539-544.

Koch, J.C., 1917. The laws of bone architecture. Am. J. Anatomy 21, 177-298.

Kuiper, J.H., Huiskes, R., Weinans, H., Year Bone remodeling: comparing local adaptation and global optimisation. In XIII ISB Congress Book of Abstracts- Perth, Australia. Perth, Australia.

Kutzner, I., Heinlein, B., Graichen, F., Bender, A., Rohlmann, A., Halder, A., Beier, A., Bergmann, G., 2010. Loading of the knee joint during activities of daily living measured in vivo in five subjects. Journal of Biomechanics 43, 2164-2173.

Lambers, F.M., Schulte, F.A., Kuhn, G., Webster, D.J., Muller, R., 2011. Mouse tail vertebrae adapt to cyclic mechanical loading by increasing bone formation rate and decreasing bone resorption rate as shown by time-lapsed in vivo imaging of dynamic bone morphometry. Bone $49,1340-1350$.

Lanyon, I.E., 1980. Bone remodelling, mechanical stress, and osteoporosis, in: De Luca, H.F. (Ed.), Osteoporosis. University Park Press, Baltimore, pp. 129-138.

Ledet, E.H., D'Lima, D., Westerhoff, P., Szivek, J.A., Wachs, R.A., Bergmann, G., 2012. Implantable sensor technology: from research to clinical practice. J Am Acad Orthop Surg 20, 383-392.

Lin, H.S., Liu, Y.K., Adams, K.H., 1978. Mechanical response of the lumbar intervertebral joint under physiological (complex) loading. J Bone Joint Surg Am 60, 41-55.

Lochmüller, E.-M., Groll, O., Kuhn, V., Eckstein, F., 2002. Mechanical strength of the proximal femur as predicted from geometric and densitometric bone properties at the lower limb versus the distal radius. Bone 30, 207-216.

Lochmüller, E.M., Poschl, K., Wurstlin, L., Matsuura, M., Muller, R., Link, T.M., Eckstein, F., 2008. Does thoracic or lumbar spine bone architecture predict vertebral failure strength more accurately than density? Osteoporos Int 19, 537-545.

Long, J.P., Santner, T.J., Bartel, D.L., 2009. Hip resurfacing increases bone strains associated with short-term femoral neck fracture. Journal Orthopaedic Research 27, 1319-1325.

Lotz, J.C., Cheal, E.J., Hayes, W.C., 1991. Fracture prediction for the proximal femur using finite element models: Part I--Linear analysis. J Biomech Eng 113, 353-360.

Luo, J., Bertram, W., Sangar, D., Adams, M.A., Annesley-Williams, D.J., Dolan, P., 2010. Is kyphoplasty better than vertebroplasty in restoring normal mechanical function to an injured spine? Bone 46, 1050-1057. 
Martens, M., Van Audekercke, R., De Meester, P., Mulier, J.C., 1981. The geometrical properties of human femur and tibia and their importance for the mechanical behaviour of these bone structures. Arch Orthop Trauma Surg 98, 113-120.

Martin, R.B., Burr, D.B., 1982. A hypothetical mechanism for the stimulation of osteonal remodelling by fatigue damage. J Biomech 15, 137-139.

McDonald, K., Little, J., Pearcy, M., Adam, C., 2010. Development of a multi-scale finite element model of the osteoporotic lumbar vertebral body for the investigation of apparent level vertebra mechanics and micro-level trabecular mechanics. Med Eng Phys 32, 653-661.

Michelson, J.D., Myers, A., Jinnah, R., Cox, Q., Van Natta, M., 1995. Epidemiology of hip fractures among the elderly. Risk factors for fracture type. Clin Orthop Relat Res., 129-135.

Minns, R.J., Bremble, G.R., Campbell, J., 1975. The geometrical properties of the human tibia. J Biomech 8, 253-255.

Morlock, M.M., Bishop, N., Rüther, W., Delling, G., Hahn, M., 2006. Biomechanical, morphological, and histological analysis of early failures in hip resurfacing arthroplasty. Proc. Instn. Mech. Engrs. Part H: J. Engineering in Medicine 220, 333-344.

Mullender, M.G., Huiskes, R., Weinans, H., 1994. A physiological approach to the simulation of bone remodeling as a self-organizational control process. J Biomech 27, 1389-1394.

Mundermann, A., Dyrby, C.O., D'Lima, D.D., Colwell, C.W., Jr., Andriacchi, T.P., 2008. In vivo knee loading characteristics during activities of daily living as measured by an instrumented total knee replacement. J Orthop Res 26, 1167-1172.

Murray, D.W., Little, J.P., Steffan, R., Fouget, P., S., K., Gundle, R., McLardy-Smith, P., Year Femoral neck fractures following resurfacing. In IMechE Conference: Engineers \& Surgeons: joined at the hip. London.

Nankaku, M., Kanzaki, H., Tsuboyama, T., Nakamura, T., 2005. Evaluation of hip fracture risk in relation to fall direction. Osteoporos Int 16, 1315-1320.

Noble, D., 2006. The Music of Life: Biology beyond the genome. Oxford University Press, Oxford, UK.

Oakland, R.J., Furtado, N.R., Wilcox, R.K., Timothy, J., Hall, R.M., 2009. Preliminary biomechanical evaluation of prophylactic vertebral reinforcement adjacent to vertebroplasty under cyclic loading. The Spine Journal 9, 174-181.

Öhman, C., Baleani, M., Perilli, E., Dall'Ara, E., Tassani, S., Baruffaldi, F., Viceconti, M., 2007. Mechanical testing of cancellous bone from the femoral head: Experimental errors due to off-axis measurements. Journal of Biomechanics 40, 2426-2433.

Parkkari, J., Kannus, P., Palvanen, M., Natri, A., Vainio, J., Aho, H., Vuori, I., Jarvinen, M., 1999. Majority of hip fractures occur as a result of a fall and impact on the greater trochanter of the femur: a prospective controlled hip fracture study with 206 consecutive patients. Calcif Tissue Int 65, 183-187.

Pidaparti, R.M.V., Turner, C.H., 1997. Cancellous bone architecture: advantages of nonorthogonal trabecular alignment under multidirectional joint loading. J Biomech. 30, 979983. 
Prakash, Prabhu, L.V., Saralaya, V.V., Pai, M.M., Ranade, A.V., Singh, G., Madhyastha, S., 2007. Vertebral body integrity: a review of various anatomical factors involved in the lumbar region. Osteoporos Int 18, 891-903.

Raftopoulos, D.D., Qassem, W., 1987. Three-dimensional curved beam stress analysis of the human femur. J. Biomed. Eng. 9, 356-366.

Roesler, H., 1987. The history of some fundamental concepts in bone biomechanics. J Biomech. 20, 1025-1034.

Roux, W., 1881. Der Kampf der Theile im Organismus. Engelmann, Leipzig.

Ruimerman, R., Hilbers, P., van Rietbergen, B., Huiskes, R., 2005a. A theoretical framework for strain-related trabecular bone maintenance and adaptation. J Biomech 38, 931-941.

Ruimerman, R., Van Rietbergen, B., Hilbers, P., Huiskes, R., 2005b. The effects of trabecularbone loading variables on the surface signaling potential for bone remodeling and adaptation. Ann Biomed Eng 33, 71-78.

Rybicki, E.F., Simonen, F.A., Weis, E.B., 1971. On the mathematical analysis of stress in the human femur. J Biomech. 5, 203-215.

Schlegel, U.J., Siewe, J., Bitsch, R.G., Koebke, J., Eysel, P., Morlock, M.M., 2010. Influence of cementing the pin on resistance to fracture in hip resurfacing. Clin Biomech (Bristol, Avon).

Schultz, A., Andersson, G., Ortengren, R., Haderspeck, K., Nachemson, A., 1982. Loads on the lumbar spine. Validation of a biomechanical analysis by measurements of intradiscal pressures and myoelectric signals. J Bone Joint Surg Am 64, 713-720.

Shah, J., Hampson, W., Jayson, M., 1978. The distribution of surface strain in the cadaveric lumbar spine. J Bone Joint Surg Br 60-B, 246-251.

Shah, J.S., Coggins, J., Rogers, R., Jayson, M.I., Hampson, W.G., 1976. Surface strain distribution in isolated single lumbar vertebrae. Ann Rheum Dis 35, 51-55.

Sheng, S.-R., Wang, X.-Y., Xu, H.-Z., Zhu, G.-Q., Zhou, Y.-F., 2009. Anatomy of large animal spines and its comparison to the human spine: a systematic review. European spine journal 19, 46-56.

Singh, M., Nagrath, A.R., Maini, P.S., 1970. Changes in trabecular pattern of the upper end of the femur as an index of osteoporosis. J. Bone Jt. Surg. Am. 52, 457-467.

Taddei, F., Palmadori, I., Taylor, W.R., Heller, M.O., Bordini, B., Toni, A., Schileo, E., IN PRESS. Safety factor of the proximal femur during gait: a population- based finite element study (S.M. Perren ESB Award paper). J Biomechanics.

Taylor, D., Prendergast, P.J., 1997. A model for fatigue crack propagation and remodelling in compact bone. Proc Inst Mech Eng H 211, 369-375.

Teo, E.C., Paul, J.P., Evans, J.H., Ng, H.W., 2001. Experimental investigation of failure load and fracture patterns of $\mathrm{C} 2$ (axis). J Biomech 34, 1005-1010.

van den Kroonenberg, A.J., Hayes, W.C., McMahon, T.A., 1996. Hip impact velocities and body configurations for voluntary falls from standing height. Journal of biomechanics 29,807 811.

van der Meulen, M.C., Huiskes, R., 2002. Why mechanobiology? A survey article. J Biomech $35,401-414$. 
van Oers, R.F., Ruimerman, R., Tanck, E., Hilbers, P.A., Huiskes, R., 2008. A unified theory for osteonal and hemi-osteonal remodeling. Bone 42, 250-259.

van Oers, R.F., van Rietbergen, B., Ito, K., Huiskes, R., Hilbers, P.A., 2011. Simulations of trabecular remodeling and fatigue: is remodeling helpful or harmful? Bone 48, 1210-1215.

Viceconti, M., Taddei, F., Cristofolini, L., Martelli, S., Falcinelli, C., Schileo, E., 2012. Are spontaneous fractures possible? An example of clinical application for personalised, multiscale neuro-musculo-skeletal modelling. J Biomech 45, 421-426.

Webster, D., Muller, R., 2011. In silico models of bone remodeling from macro to nano--from organ to cell. Wiley Interdiscip Rev Syst Biol Med 3, 241-251.

Wehner, T., Claes, L., Simon, U., 2009. Internal loads in the human tibia during gait. Clin Biomech (Bristol, Avon) 24, 299-302.

WHO, 1994. Assessment of fracture risk and its application to screening for postmenopausal osteoporosis. Report of a WHO study group. WHO Technical Report Series, World Health Organization, Geneva, Switzerland, 843: 1-130.

WHO, 2007. Scientific group on the assessment of osteoporosis at primary health care level, p. 17.

Wolff, J., 1892. Das Gesetz der Transformation der Knochen. Verlag von August Hirschwald, Berlin.

Yang, K.-H.-., Shen, K.L., Demetropoulos, C.K., King, A.I., Kolodziej, P., Levine, R.S., Fitzgerald, R.H.J., 1996. The relationship between loading conditions and fracture patterns of the proximal femur. J. Biomech. Eng. 118, 575-578.

Zani, L., Cristofolini, L., Juszczyk, M., Viceconti, M., 2012. In vitro strain distribution during sideways fall in the proximal human femur. J Biomech 45, s351.

Zani, L., Cristofolini, L., Juszczyk, M.M., Grassi, L., Viceconti, M., 2014. A new paradigm for in vitro simulation of sideways fall loading of the proximal human femur. Journal of Mechanics in Medicine and Biology 14, 1450005 (1450020 pages).

Zani, L., Erani, P., Grassi, L., Taddei, F., Cristofolini, L., SUBMITTED. Strain distribution in the proximal femur in a sideways fall: a detailed in vitro investigation J Biomechanics. 


\section{CAPTIONS AND FIGURES}

\section{Range of physiological \\ loading directions}

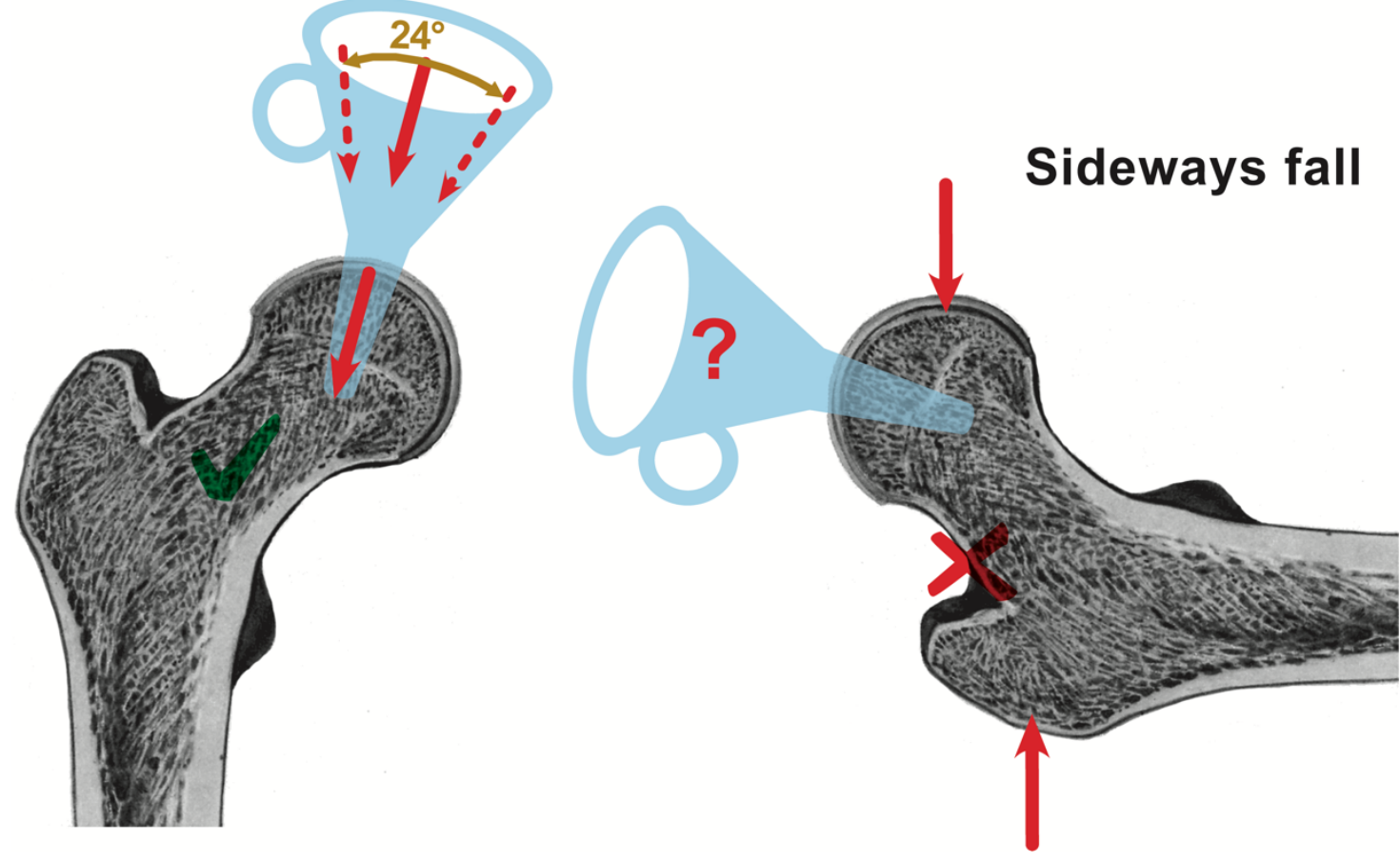

Fig. 1 - The multiscale arrangement of anisotropic and inhomogeneous properties of the proximal femur generates a sort of "funnel effect". LEFT: when a force is applied to the femoral head within a range of directions (corresponding to the physiological range), this makes the directions of principal strain converge to well-defined directions (which correspond to the strongest directions of the anisotropic tissue at each point). RIGHT: Conversely, if a force is applied in a different direction (e.g. during a sideways fall) such an effect is not reached and the directions of principal strain can be quite different from the strongest structural directions. 


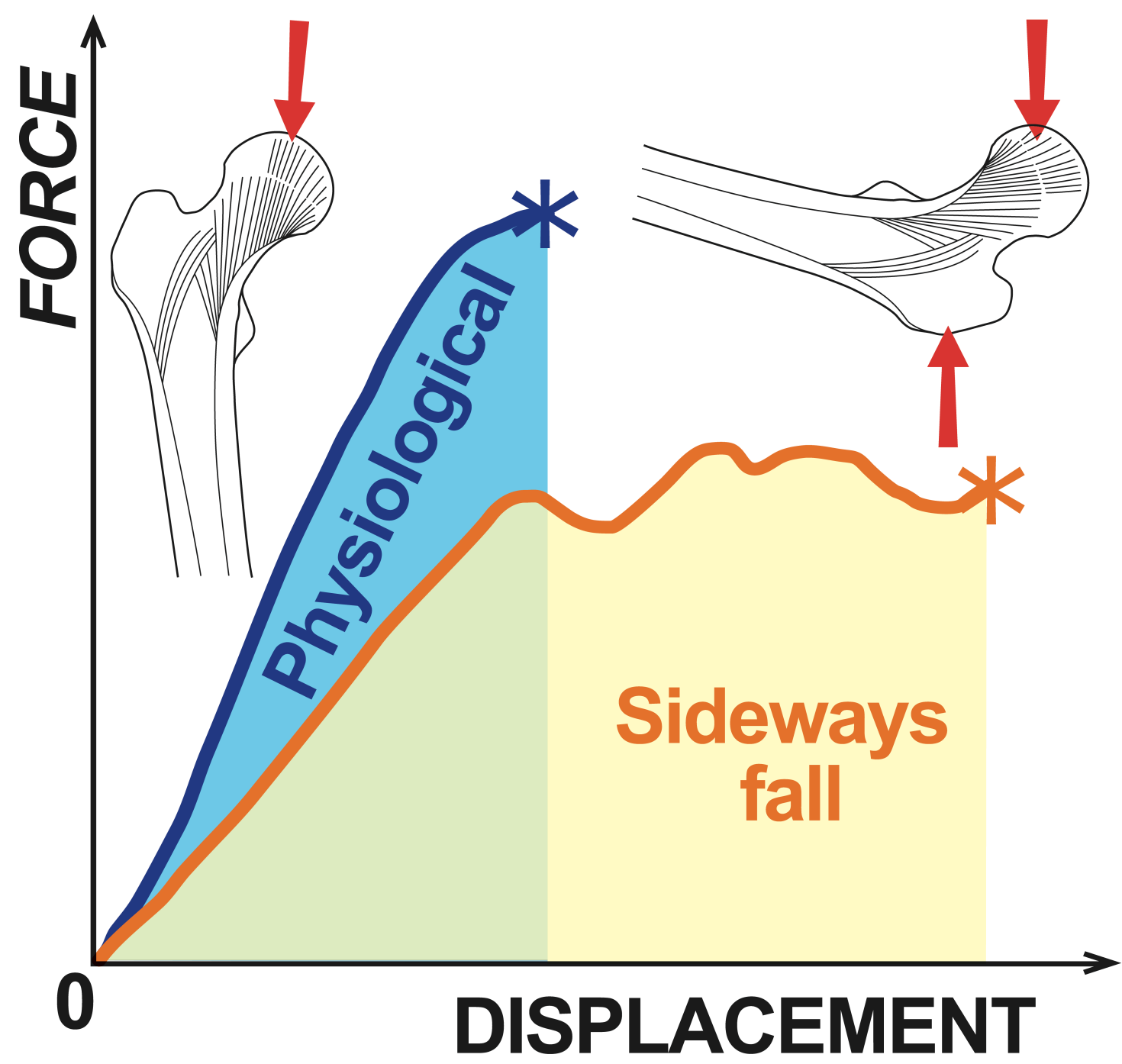

Fig. 2 - Qualitative force-displacement plot for a femur undergoing two different loading conditions: stiffness and high maximal force predominate for physiological loading, while a large energy is needed to cause a complete fracture during a sideways fall. 


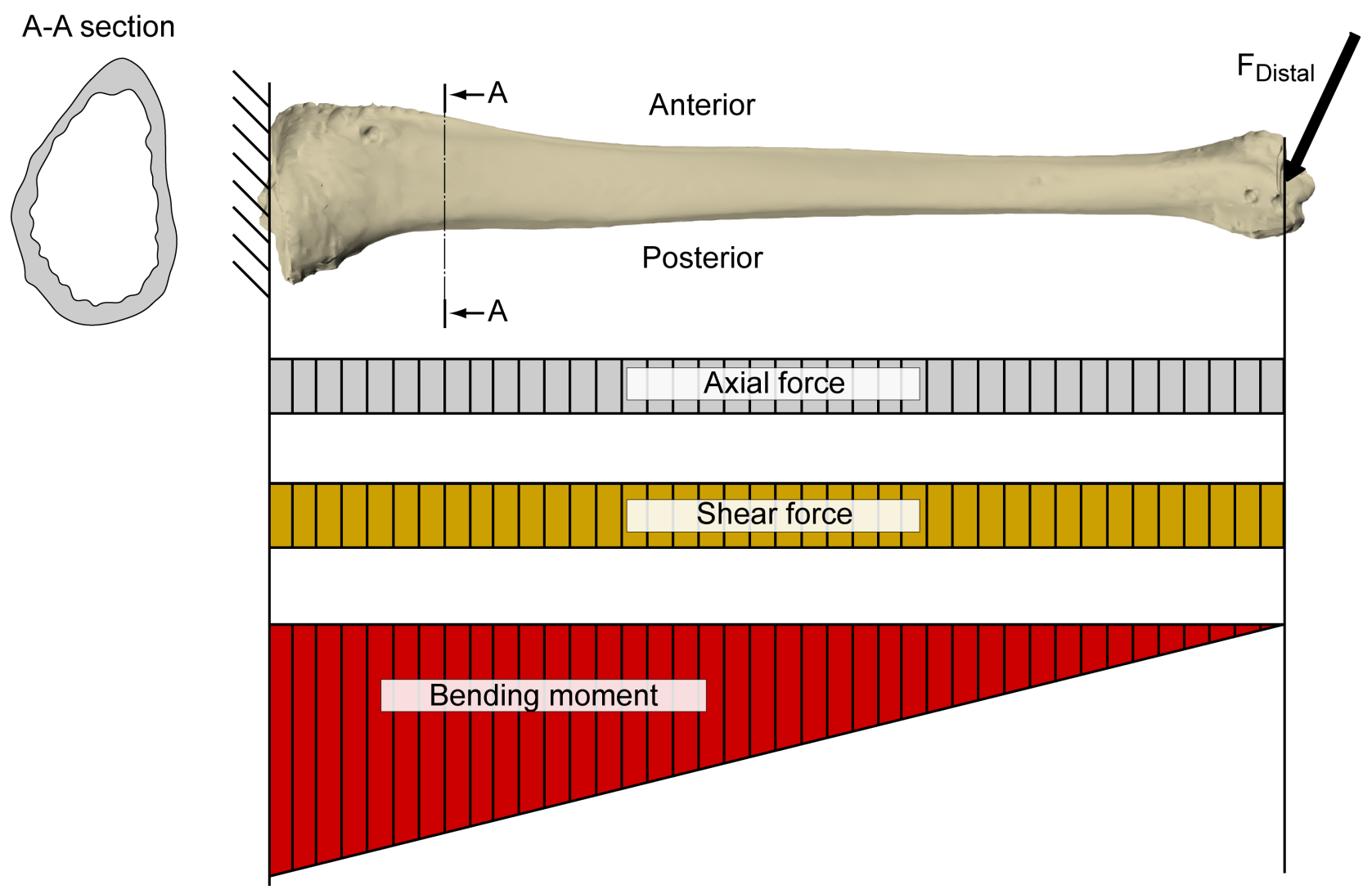

Fig. 3 - Lateral view of a human tibia: the variation of cross-section along its axis is visible. Also indicated is a schematization of the physiological loading condition: a force is applied at the distal end in the sagittal plane. The axial component of such a force generates compression. The antero-posterior component generates a cantilever condition, where the bending moment varies linearly along the tibial axis. 

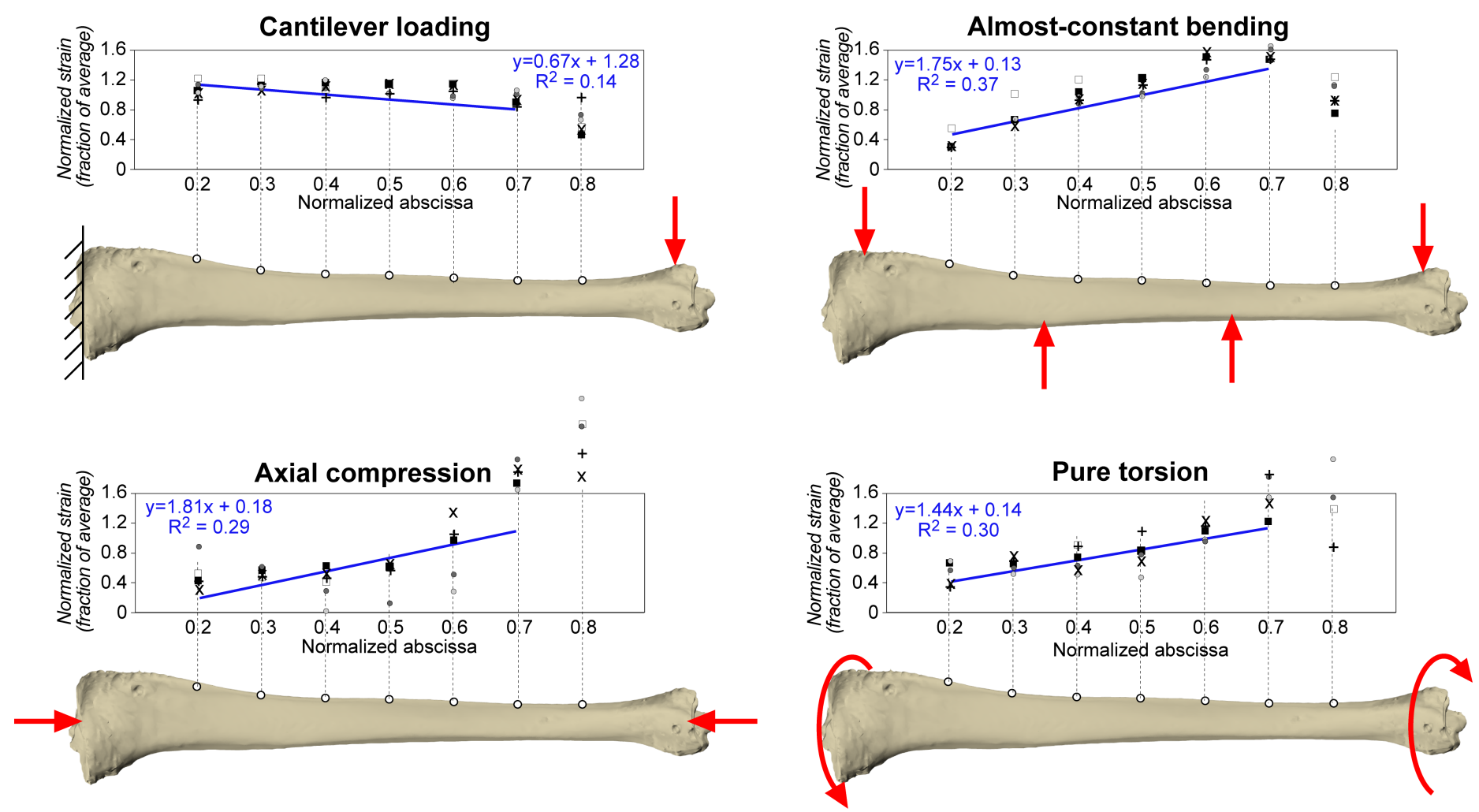

Fig. 4 - Strain distribution on the anterior side of the tibia for different loading conditions: cantilever loading (maximal bending moment proximally) in the sagittal plane; four-point-bending (almost-constant bending moment along the tibia) in the sagittal plane; axial compression; torsion. For each specimen (6 are plotted) principal strain at each strain gauge is reported as a fraction of the absolute value of the average between the 7 strain gauges. The strain distribution for the cantilever loading in the sagittal plane is fare more uniform than for any other loading configuration. Adapted from (Cristofolini et al., 2013a). 

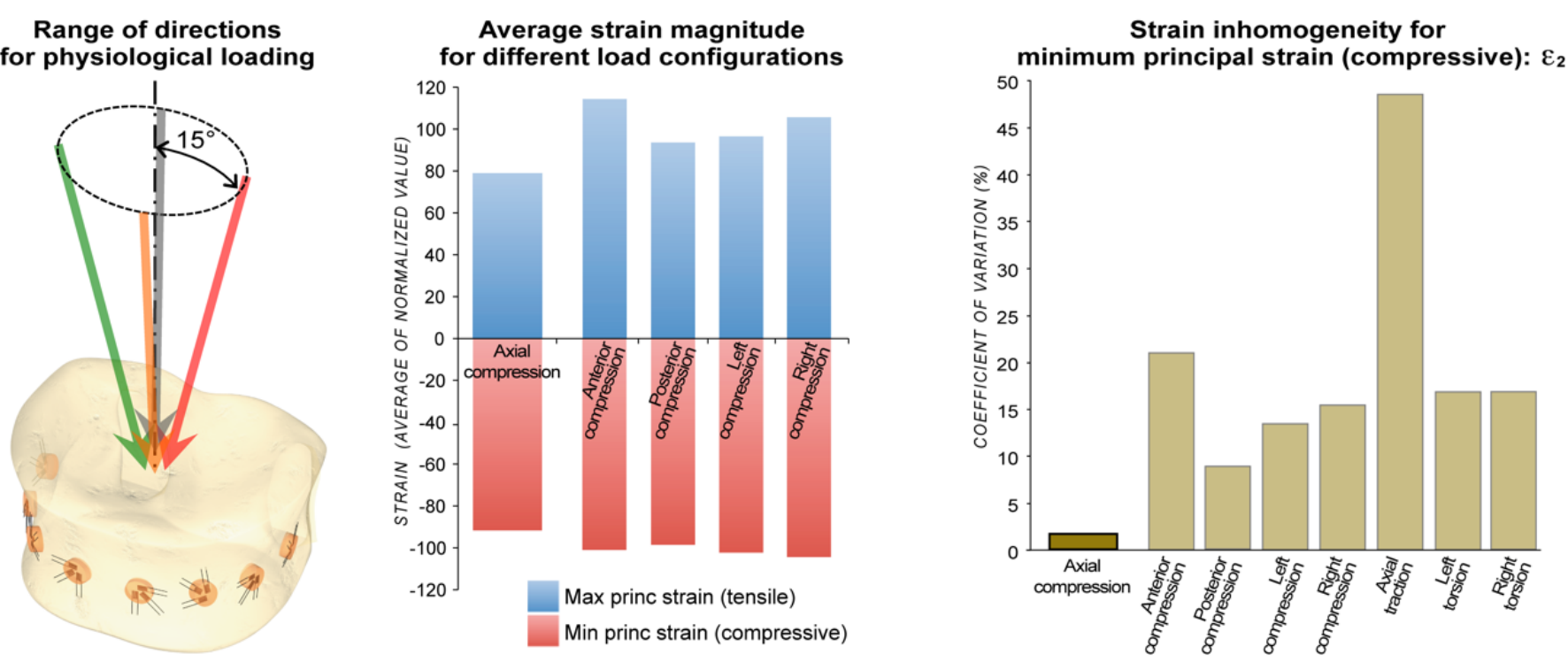

Fig. 5 - The vertebral body seems to be designed to withstand an axial force. LEFT: cone spanned by the resultant forces during daily activities (Bergmann, 2013). CENTRE: strain is lower when the compressive force is aligned with the vertebral body, compared to the cases where the force was tilted by $15^{\circ}$ in any direction (to enable comparison between the different loading configurations, for each strain gauge, each strain component is normalized with respect to the average between the five loading configurations; the average between eight measurement locations on each vertebra is plotted; data adapted from (Cristofolini et al., 2013b)). RIGHT: when an axial force is applied strain gradients are much lower than for any other type of loading (the strain inhomogeneity for the different loading configurations is computed as standard deviation between strain measurement locations, for the compressive principal strain; data adapted from (Cristofolini et al., 2013b)). 


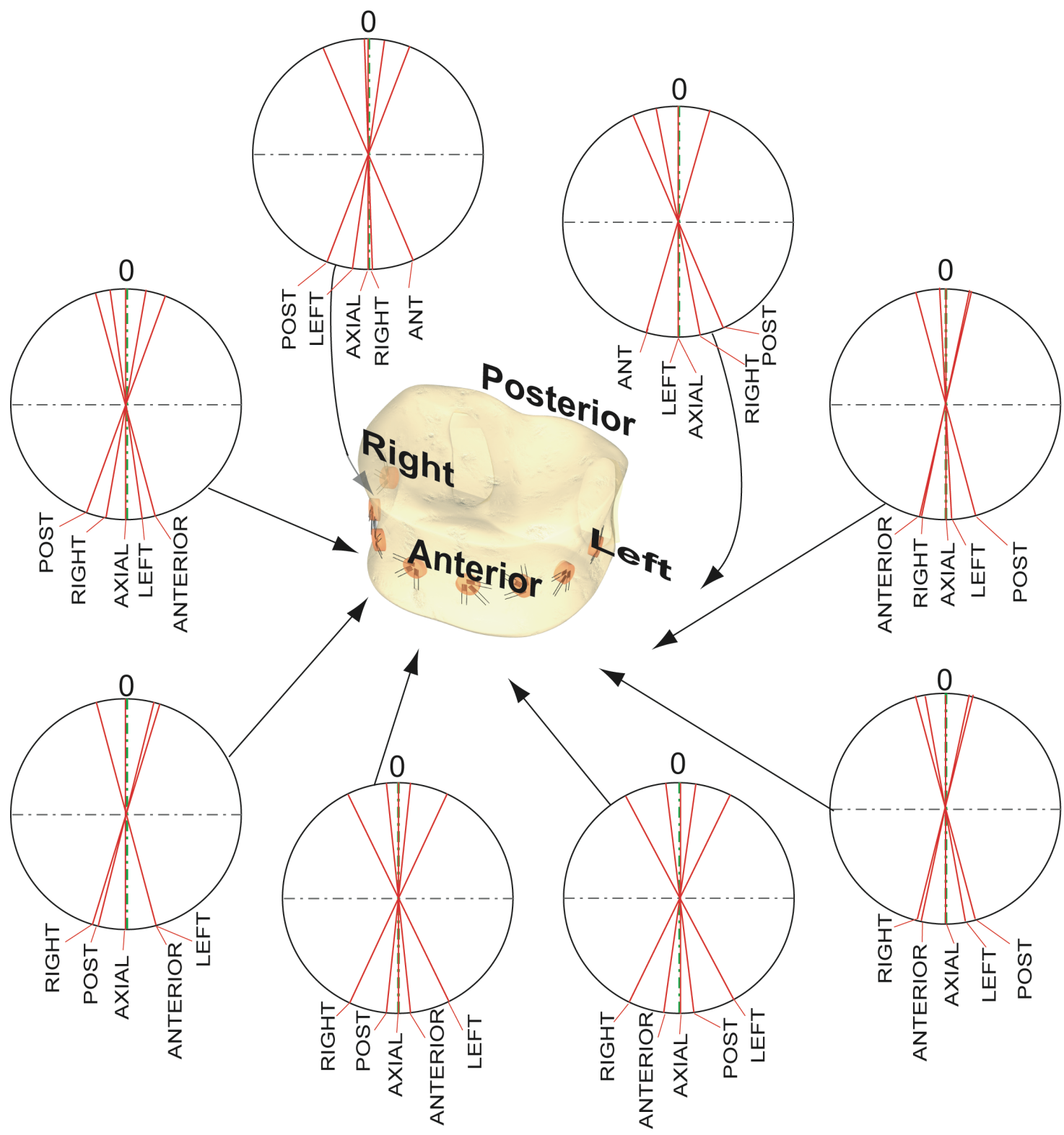

Fig. 6 - The vertebral body seems to be designed to withstand an axial force: when the force is tilted by $15^{\circ}$ in any direction (anterior, posterior, right, left) within the $30^{\circ}$ cone, the alignment of principal compressive strains becomes quite different from the alignment of the trabeculae (i.e. the strongest direction of the bone) (Cristofolini et al., 2013b). 


\section{TABLES}

Table 1 - Strain values measured in vitro when physiological motor tasks are simulated. When available, forces are expressed in Body weight (BW).

Motor task
$\begin{aligned} & \text { In vitro experiment } \\ & \text { (Field and }\end{aligned} \quad \mathrm{F}=1500 \mathrm{~N}$ at $16^{\circ}$ in the frontal plane
$\begin{array}{ll}\text { Rushton, 1989) } \\ \text { (Cristofolini et }\end{array}$
$\begin{array}{ll}\text { Single leg stance, walk }(\mathrm{F}=2.5 \mathrm{BW}) \\ \text { al., 2009) } & \text { Stumbling }(\mathrm{F}=8.7 \mathrm{BW})\end{array}$

\section{In vivo measurements}

(Aamodt et al., One-leg stance

1997) Walking

Stair Climbing

\section{Physiological ranges}

(Lanyon, 1980) Bone resorption/formation

(Bayraktar et al., Bone tissue fracture

2004)

\section{Measured strain (microstrain)}

Range: -1800 to +1200

Max tensile: +735 , Max compressive: -1029

Max tensile: +5760 to 8468 Max compression: -11850

Range: -435 to +1463

Range: -393 to +1198

Range: -948 to +1454

Approximately 1000

Tensile: +7300 , Compressive: -10000

\section{Note}

Peak value out of 17 uniaxial strain gauges

Average of 12 locations, 24 femurs Local peak

One strain triaxial strain gauge on the lateral proximal part of the femur 